\title{
The Pandemic of Conflict-Related Sexual Violence and the Political Economy of Gender Inequality
}

\author{
Sara E. Davies and Jacqui True
}

\section{Introduction}

Since the 1998 Rome Statute recognised widespread and systematic acts of sexual and gender-based violence (SGBV) as an act of genocide, a war crime and crime against humanity, the last decade has seen historic recognition that egregious acts of sexual violence merit international political and legal attention (UN General Assembly, 1998). Notably, there are now no fewer than seven United Nations Security Council resolutions on the cross-cutting theme of Women, Peace and Security. $<$ xen $>1</$ xen $>$ This significant international attention on sexual violence in armed conflict was further heightened with the launch of the United Kingdom's Prevention of Sexual Violence Initiative (PSVI) in May 2012 by Foreign Secretary William Hague. Thus far, the PSVI has prompted a G8 Declaration (April 2013), a Security Council Resolution, $<$ xen $>^{2}</$ xen $>$ the United Nations General Assembly Declaration of Commitment to End Sexual Violence in Conflict (September 2013) supported by 150 states, and a new International Protocol on the Documentation and Investigation of Sexual Violence in Conflict (June 2014) (UK FCO, 2014). These actions illustrate the high-level political actions being taken to address sexual violence in conflict around the world. Yet current research on the early warnings of 'widespread and systematic' sexual violence in conflict discounts the relevance of structural gender inequality in the prevention of these atrocities.

In this chapter we examine the extent to which structural gender inequality is considered in studies of conflict-related sexual violence that are informed by these international developments. We argue that researchers have not adequately or consistently established the presence or absence of a relationship between gender inequality and sexual violence in armed conflict. Rather, they have selectively used 
conflict data, definitions of SGBV, thresholds for mass sexual violence, and single sources of evidence to support their arguments. Thus the findings from this body of research are neither sufficiently rigorous nor generalisable to be able to eliminate structural gender inequality as an explanation for the conditions giving rise to widespread and systematic SGBV. We illustrate this argument with reference to the pattern of SGBV in both conflict and post-conflict periods in Sri Lanka. Addressing the key problematic of the volume, we argue that promoting gender justice for victims of conflict-related SGBV involves recognising sexual violence crimes as political crimes that seek to deny representation and redistribution towards those targeted.

The chapter unfolds in three parts. First, we explore the causal analysis of SGBV and argue that it fails to understand the gendered nature of the drivers of SGBV (Cohen $\&$ Nordas, 2014; Wood, 2012). Second, we illustrate why a critical feminist insight into SGBV is essential to illuminate the early contributory risk that gender inequality poses in SGBV. Here, we turn to the case of Sri Lanka since the end of the civil war in 2009. Third, we summarise why an understanding of SGBV that incorporates the gendered political relationship between SGBV and structural gender inequality is essential to restore access to justice. To recognise the dangers of silence on SGBV in conflicts and to begin addressing political representation and recognition for survivors requires us to move beyond criminal justice and the socialisation and accountability of perpetrators.

\section{The emerging international norm against sexual violence in armed conflict}

'Widespread and systematic' SGBV was first defined under international law in the 1998 Rome Statute of the International Criminal Court (ICC). SGBV crimes, which include rape and other forms of sexual and non-sexual attacks on women and girls, boys and men, are defined as such by the ICC because of 'persecution on the grounds of gender' (Office of the ICC Prosecutor, 2014, p. 12). 'Gender' here does not refer to 'biological sex' or to people called 'women', but rather to the attempt to achieve masculine dominance over 'others' through rape and sexual and other forms of violence where the intention is to 'feminise' and shame victims, their families and communities. The Office 
of the ICC Prosecutor considers sexual violence crimes in addition to rape, such as sexual assault, slavery, abduction and forced pregnancy. Sexual violence crimes are perpetrated by more than one side in a conflict, by state and non-state actors, by males and females. They are also crimes occurring outside of conflict, with few victims and one or many locations. What defines all of these acts is that they involve persecution on the basis of gender (masculine dominance over feminised subjects) and are carried out by individuals, but where institutions (military/militia, prisons, equipment, laws, security and justice) implicitly or explicitly support them (Office of the ICC Prosecutor, 2014).

The UN Security Council (UNSC) recognises SGBV crimes under the Rome Statute but also recognises SGBV as a threat to international peace and security since the adoption of Resolution 1325 (UNSC 2000). As noted, there have been seven UNSC resolutions on the cross-cutting thematic Women, Peace and Security agenda, passed since Resolution 1325 (UNSC 2000). These refer to the responsibility of Member States to pursue violators of sexual violence in armed conflict (SVAC) and recommend measures to prevent these acts. Resolutions 1888 (UNSC 2009a), 1889 (UNSC 2009b), 1960 (UNSC 2010), 2106 (UNSC 2013a) and 2122 (UNSC 2013b) have increasingly focused on sexual violence only in armed conflict situations. Resolution 1888 (2009) requires the secretary-general to provide annual reports on SVAC. This is arguably the most successful and compelling call to action to protect victims of SVAC (Kirby, 2012).

In the 2012 inaugural report on situations of SVAC, the UN secretary-general referred to cases under the categories 'conflict', 'post-conflict' and 'elections, political strife and/or civil unrest' (at the time, the political protests in Egypt fell into this last category). Some Member States of the UNSC opposed that report, including two permanent members (China and Russia). It led to the successive 2013 and 2014 reports to remove the 'elections, political strife and/or civil unrest' category (Security Council Report, 2014, p. 5). However, the 'post-conflict' category of cases has remained on the Security Council agenda and the secretary-general still raises 'other situations of concern' (UN Secretary-General, 2013, 2014). The reference to 'sexual violence in conflict' is a political attempt by the Security Council to delimit the discussion of SGBV and does not follow from the legal norm as established in the Rome Statute. 
The defining feature of SGBV crimes in pre-conflict, conflict and post-conflict contexts is that they have become 'normalised' within a given environment and there is a risk of them becoming 'systematic' (Baaz \& Stern, 2013; Kirby, 2012). Key markers of 'widespread and systematic' are when additional identifying features lead to particular groups being targeted for attack, being subjected to the same type of attack, being attacked by the same group of perpetrators, and when there is impunity for the attacker (Goetz, 2008). Given this, much of the focus on early warning and prevention of SGBV crimes should be dedicated to situations outside of conflict, and countries where there are serious levels of societal gender inequality that would highlight the groups further vulnerable to SGBV. However, this is not the case in most of the research on the cause(s) of SGBV, as is discussed below.

\section{Explaining the causes of sexual violence in conflict}

Since the passage of Resolution 1325 (2000), in the current literature there have been two major explanations provided for mass SGBV based on the study of patterns across four or more cases of armed conflict. $<$ xen $>^{3}</$ xen $>$ One explanation is that mass SGBV is caused by the presence or existence of armed conflict. Sexual violence occurs when there are perpetrator dynamics, such as type of recruitment and socialisation in the armed group that fuel these crimes. In this research, sexual violence is viewed as a primarily opportunistic crime carried out by individuals in armed groups. The other major explanation is that mass sexual violence is a deliberate collective strategy deployed against civilians for the purpose of war gain or plunder, enabling the acquisition of resources, land and power. Neither explanation, as we will illustrate, is informed by an analysis of the relationship between structural gender inequality and political violence. We turn to this third, alternative explanation - critical feminist analysis of sexual violence - to provide new insight into the factors that could identify high-risk situations of SGBV toward the development of more effective early warning frameworks. $<$ xen $>^{4}</$ xen $>$

Wood's (2006) study of eight cases ranging from the Second World War to the Salvadoran civil conflict and the US-led war in Vietnam is one of the first to examine the 
varied use of SVAC. Wood asks: if sexual violence is a 'strategic tool' for waging war, then why do armed groups inconsistently use it? She draws on existing studies to compare 'non-event' cases where allegations of the perpetration of sexual violence by at least one-armed group involved in the conflict were ostensibly 'absent'. She defines 'absence' as the rare or minimal reporting of sexual violence. Exploring a number of existing hypotheses, she found little support for explanations of the use of sexual violence based on the type of conflict, the instrumentality of SGBV to the group, the militarisation of masculinity or pre-existing, uneven gender relations. For each of these potential explanations, Wood uses the method of falsification, pointing to an anomalous case that she claims disproves it. The presence of gender inequalities that predate conflicts is dismissed, because to include it would imply that sexual violence should be more prevalent in wars in which traditional gender norms are disrupted (Wood, 2006, p. 325). $<$ xen $>^{5}</$ xen $>$ She also states that gendered social relations cannot account for the targeting of particular individuals and groups for sexual violence because all groups have these unequal, power dynamics, but not all groups perpetrate sexual violence.

Based on her falsification of potential explanations, Wood (2006) argues that the most compelling explanation for sexual violence was the individual opportunity to commit violence, facilitated by the lack of a hierarchical command structure and explicit norms against sexual violence within armed groups. Wood's study has spurred a debate within political science and international relations on the primary drivers of SVAC; between those scholars who argue that SGBV is largely 'opportunity-driven' (Butler et al., 2007; Cohen, 2013) and those who argue it is a 'deliberate strategy' informed by the context of the conflict itself (Farr, 2009). Studies that distinguish strategic SGBV from opportunistic SGBV tend to focus on the scale of sexual violence (low to high prevalence) being reported (isolated reports versus numerous reports) (Butler et al., 2007; Cohen, 2013). However, this attention to the scale of sexual violence perpetrated in a conflict ignores the selective but widespread use of gendered violence against a group or members within it. This is explored by Butler and colleagues (2007), who focus on the opportunistic sexual violence facilitated by the breakdown of control and discipline within the perpetrator armed group. 
Farr (2009) challenges the studies by Wood (2006) and Butler and colleagues (2007), suspecting that there may be crucial differences in the use of SGBV across types of conflict and perpetrator. She compares war rape in 27 armed conflicts reported by Project Ploughshares in 2007. Like others, Farr (2009, p. 6) does not refer to the 1998 Rome Statute's definition of 'widespread and systematic' SGBV, but notes the studies of 'extreme war rape', defined as 'regularized, war-normative acts of sexual violence accompanied by intentional serious harm, including physical injury, physical and psychological torture, and sometimes murder'. Farr's study is one of the few references to sexual violence as being part of a broader pattern of political violence against a particular group. Similar to Bastick and colleagues (2007), Farr (2009, p. 10) is less concerned with explaining the scale of sexual violence in war than with understanding 'differences in the prevalence and prominence of particular rape sites, perpetrator groups, and victim targets'. From 27 cases, she identifies 4 war rape patterns: fieldcentred/opportunistic; field-centred/woman-targeted; state-led/ethnic-targeted; and stateled/enemy-targeted.

Contesting previous findings, Wood's analysis reveals varied reports of conflictrelated sexual violence and different motivations and targets of violence depending on the context of the conflict and what combatants were fighting over. In the conflicts she analysed, such as those in Liberia and the Democratic Republic of Congo, where strong rebel groups were fighting to gain control over valuable resources in a country, SGBV tended to be highly prevalent and perpetrated by both rebels and state agents in the field area where the fighting was occurring (field-centred/opportunistic). Thus, rape may have a strong opportunistic component as well as a 'strategic' purpose. Field-centred/womantargeted rape occurred more often in conflicts such as Afghanistan and Iraq where both state and rebel groups were perpetrators, with women specifically targeted for their 'deviant' social behaviour, including dress, appearance in public, political activism and so on. State-led/ethnic-targeted rape was perpetrated in contexts like Chechnya and Myanmar, where a powerful, controlling state attempted to quash a smaller secessionist or minority-representing group. In this category, rape victims were often targeted based on ethnicity. Finally, state-led/enemy-targeted rape tends to target victims based on ideological affiliations with rebel groups and activism critical of the state. In this 
situation, large and powerful rebel groups appear to have committed little SGBV, while state security forces tend to have employed SGBV as a means of repression (for example, in Sri Lanka, see below). However, as Farr (2009) acknowledges, these findings are limited to situations already involving violent conflict. What is not clear is whether the motivations for different groups to deploy SGBV shift across the phases of conflict, before, after and during armed fighting.

Like Farr, Green (2006) examines 'collective' rape as a gendered form of political violence, but she explores the phenomenon irrespective of the presence of conflict and draws from multiple sources for reports of sexual violence. Collective rape is defined as 'a pattern of sexual violence perpetrated on civilians by agents of a state, political group and/or politicized ethnic group' (Green, 2006, p. ii). Patterns of 'collective' rape on a global scale are measured drawing on English language news reports of mass rape from 1980 to 2003. Green finds confirmation for the hypothesis that conflict intensity and militarisation drive collective rape. On the question of the relationship between gender inequality and SGBV, however, she argues that the presence of conflict would have affected the gender indicator scores. $<$ xen $>^{6}<$ xen $>$ Green does not appear to take into account that gender inequality is a political objective and that SGBV crimes are political acts in those situations where gender oppression enables the achievement of political objectives.

More recently, Cohen (2013) has examined sexual violence specifically in civil conflicts (defined by the Fearon and Laitin (2003) Civil War data set). Sexual violence is measured on a scale of intensity (0-4) and the reporting source (US State Department annual reports) is replicated from the study of Butler and colleagues' (2007). Cohen finds no statistically significant evidence of a relationship between sexual violence and ethnic hatred, ethnic cleansing or genocide, nor any relation to gender inequality operationalised using proxy variables from the Cingarelli and Richards Human Rights data set on women's economic, social and political rights, and fertility rates. Above all, Cohen identifies perpetrator socialisation to be the most likely cause of SGBV. She suggests that early warning analysis should consider reports of abductions by armed groups as a sign of the escalating threat of wartime rape, which is especially acute under conditions of state 
collapse and in the presence of resources for plunder. However, we contend that the recruitment strategies or moral codes of armed groups cannot be considered 'genderneutral' explanations. Soldiers and rebels are affected by socially constructed and culturally specific gender norms, which influence their treatment of groups, their tactical use of violence and the norms within their group depending on their gender make-up.

The findings of Wood, Butler et al., Green and Cohen about the permissive environment enabling perpetrator rape (more than the presence of gender inequality, ethnic grievances or the genocidal intent of the regime) have been corroborated by Cohen and Nordas (2014) using a larger conflict database (Uppsala Conflict Data Program) and expanded reporting sources, including UN and non-governmental organisation reports as well as US State Department annual reports. These studies demonstrate the extent to which current attempts to identify the 'levers' and 'mechanisms' essential to preventing SVAC do not address gendered structures, institutions and identities as 'triggers' for such violence. In particular, they do not address why combatants (military or rebels groups) use sexual and gender-based forms of violence in particular, nor do they explain which populations are going to be targeted for this form of violence. Even if we accept the opportunistic and instrumental arguments, they do not illuminate why acts of SGBV are strategically advantageous and time-efficient versus, for example, killing or (only) forcibly displacing populations.

Understanding the characteristics of a particular population targeted for this violence requires understanding why this population is being attacked - inevitably this requires an understanding of the existence of gendered inequalities and discrimination that may explain why it is instrumental or/and opportunistic to use SGBV in the first place (Baaz \& Stern, 2013; Enloe, 2000; Goldstein, 2001; Kirby, 2012; True, 2012). Fertility rates, used as the proxy for gender equality in statistical studies like Cohen's (2013), for example, tell us little about the degree of gendered inequality and discrimination within a society. They also have limited utility in revealing short- to medium-term changes in gender relations. $<$ xen $>^{7}</$ xen $>$ One objection given to the study of levels of gender violence within a society prior to the onset of SGBV in conflict is the questioning of why sexual violence needs to be examined in this way when 'other forms 
of conflict-related violence are not subjected to continuity arguments?' (Quijano \& Kelly, 2012, p. 489). $<$ xen $>^{8}</$ xen $>$ However, the Office of the ICC Prosecutor refers to these crimes as 'persecution on the grounds of gender' (Office of the ICC Prosecutor, 2014, p. 12, emphasis added). Variations in norms regarding rape and gender within and across groups, and in the phases and intensity of political violence and conflict, including situations prior to armed conflict, are relatively neglected as causal factors. This results in the relationship between political violence and the use of 'widespread and systematic' SGBV being poorly understood. The dominance of 'opportunistic' versus 'strategic' explanations of SGBV ignores the ontologically prior relationship between structural gender inequality and political violence. Even if prohibition norms are vital to addressing mass SGBV and perpetrator attitudes, values, beliefs and interests, these must themselves be explained more fully as they do not arise 'naturally' or spontaneously, nor can they explain why SGBV (and not other forms of violence) is overwhelmingly perpetrated against women and children. Indeed, the targeting of civilian populations disproportionately made up of women and children should logically lead us to want to interrogate whether structural gender inequalities affect the patterns and location of SGBV crimes. Such violence is always constructed and legitimised within a gendered social context (Enloe, 2000; True, 2012). These gendered contexts need to be understood as both part of the problem and the solution to mass sexual violence. As the Office of the ICC Prosecutor argues, understanding the differences in status, power, roles and needs between males and females enables the Office to 'gain a better understanding of the crimes, as well as the experiences of individuals and communities in a particular society' (Office of the Prosecutor, 2014, p. 3).

As well as critically analysing the gendered contexts affecting the behaviour of suspected perpetrators of SGBV crimes, we should also interrogate the collection of sexual violence data. Given that we know women are less likely to be politically represented in post-conflict situations (Buvinic et al., 2013), and that deaths (including indirect deaths due to health and disability) disproportionately affect women in postconflict situations (see Ghobarah et al., 2004; True 2012), $<$ xen $>9</$ xen $>$ the opportunity and incentive to report sexual violence is likely to be compromised. Moreover, as the Sri Lanka case reveals in the second part of this chapter, a gender analysis may reveal deeper 
insight into whether the 'reported' volume of cases relates to the actual volume given the pre-conflict existence of ethnic and political discrimination. In studies where it has been claimed that SGBV did 'not' occur, we have little understanding of what gender-sensitive analysis informed this finding (see Human Security Report Project, 2012; Wood, 2009). What the Sri Lanka case demonstrates below is that we must be careful in assuming that

silence on SGBV means it did not occur. In Sri Lanka, the prevalence of structural gender inequality is a crucial explanation and predictor of SGBV. Once we identify the risks attached to those who report these crimes, we are able to recognise and bring about gender-responsive redistribution, restoration, recognition and representation in a postconflict society.

\section{Sri Lanka and the silence on SGBV}

In exploring the brutality against civilians in the last stages of this 30 -year civil war, the UN Secretary-General's 2011 Panel of Experts on Accountability in Sri Lanka found that both the Sri Lankan armed forces and Tamil Tigers (LTTE) committed grave acts of violence, including sexual violence, amounting to crimes against humanity and war crimes (UN Secretary-General Internal Review Panel, 2012, para. 151). In particular, the report documents how Tamil women were targeted for rape and sexual violence in the final stages of the conflict by Sri Lankan armed forces. These acts were 'greatly underreported' due in part to 'cultural sensitivities and associated stigma [which] often prevented victims from reporting such crimes, even to their relatives' (UN SecretaryGeneral Internal Review Panel, 2012, para. 152). In March 2014, the UN Human Rights Council passed a resolution declaring that the Sri Lankan government was failing in its responsibility to prosecute individuals for these crimes (UN Human Rights Council 2014). In that resolution, the Office of the High Commissioner for Human Rights was called upon to investigate allegations of war crimes and crimes against humanity committed by all parties during the civil war, and to specifically address ongoing 'violations of human rights in Sri Lanka, including SGBV' (UN Human Rights Council 2014). 
It is important to analyse the Sri Lanka case in light of our current understanding of mass SGBV for two reasons. First, those scholars who view SGBV as instrumental or opportunistic tend to agree that the perpetrator is the source of prevention, but this explanation insufficiently accounts for why SGBV persists after the end of the war, with the victory of the Sri Lankan government. Second, in the few times researchers have sought to explain the Sri Lanka case it has been proposed that the existence of sexual violence within the conflict is one-sided (Farr, 2009; Human Security Report Project, 2012; Wood, 2009). Specifically, it is contended that the LTTE did not engage in sexual violence during or after the conflict due to strict prohibitions concerning sexual relations among the membership (Human Security Report Project, 2012; Wood, 2006, 2009). However, a critical feminist analysis of the gendered structures within Sri Lanka contests these explanations of the occurrence and reporting of SGBV crimes in the country. First, as we examine further below, impunity for gender violence is pervasive in Sri Lanka. Because of pervasive gender oppression, the stigma and shame attached to this violence rests with the survivor, not the perpetrator. As such, gender-based violence is being deployed to solidify the victory of the Sri Lankan government post-2009, and to further political victory over an ethnic minority population. Such violence can only be effective if we understand the constitutive relationship between gender inequality, gender violence and the nationalisation project in Sri Lanka.

This leads to the second point: given the political situation in Sri Lanka, the absence of reported SGBV violations (by either party of the conflict, LTTE and Sri Lankan armed forces) does not mean such violations have not taken place. Ethnic and religious division within Sri Lanka, coupled with creeping authoritarian rule, make it nearly impossible to appreciate the extent to which widespread and systematic SGBV crimes have been perpetrated by both LTTE rebels and the Sri Lanka military against civilian populations (as suggested in the UN Secretary-General Internal Review Panel, 2012). This is problematic for drawing a conclusive understanding about the prevalence of SGBV in Sri Lanka. However, this case does serve to illustrate the objective of SGBV - to secure political gains through use of violence that is stigmatising and shameful within that society within existing gender norms and which thus represses political opposition or resistance. 


\section{The political utility of gender violence in peace}

In the Sri Lanka case, the majority of reported SGBV victims are returning displaced persons in the impoverished northern provinces of Sri Lanka. (Nearly 500,000 were forcibly displaced during the final months of the Sri Lankan military assault on those provinces in 2009.) These victims are predominantly female returnees, including former Tamil combatants and war widows. They are in situations of extreme vulnerability due to the political and economic restrictions on Tamil access to land rights, compensation, resources and income (Minority Rights Group International, 2013). However, 'the quest for truth, justice and accountability at the community level is primarily led by women, in a way that is relatively unusual in the rest of Sri Lanka' (Minority Rights Group International, 2013, p. 14). Many Tamil women have asserted their right to compensation and land and have demanded investigation of family members in a way that is unprecedented in 'heavily patriarchal' Sri Lankan society (Minority Rights Groups International, 2013, p. 3). Consequently, it may not be a mere coincidence that Tamil women in the northern and eastern provinces have experienced extreme acts of sexual intimidation and violence by Sri Lankan military and police in a heavily policed security zone upon their return (Sooka, 2014; UN Secretary-General, 2012, p. 18).

In a patriarchal, militarised society such as Sri Lanka, the use of sexual violence by the military and police is effective because gender norms within that society promote women's subordination and modesty (Fulu et al., 2013; Gupta, 2014). $<$ xen $>^{10}</$ xen $>$ Women and men, whether Tamils, Muslims or human rights activists, who do not agree with the political agenda of the Sri Lankan government, are being subjected to SGBV to reinforce their need to comply with Sri Lankan authorities (Sooka, 2014). The UN Human Rights Council (2014) resolution noted that the continuation of political violence against minority groups within Sri Lanka - including the strategic use of SGBV - points to sustained efforts by the Sri Lankan government to ensure its decisive political victory since 2009. However, we can only understand why SGBV consolidates political victory if we understand its effects in the context of pervasive structural gendered inequality and normalisation of violence against women in Sri Lanka. 
Kodikara (2014) argues that since the 2009 victory against the LTTE there has been a 'resurgence of Sinhala Buddhist nationalism' in post-war Sri Lanka. Kodikara (2014) describes the 'valorisation' of the Sri Lankan military and the resurgence of nationalism, particularly directed towards the Sri Lankan military and police to populate the country, with bonus rewards for large families. $<$ xen ${ }^{11}</$ xen $>$ Civilian women are experiencing a dramatic curtailment of their reproductive rights, with a comprehensive crackdown on institutions that provide emergency abortions, contraceptive advice and devices. Police and public health administrators (within hospitals) are enforcing a (never repealed) decades-old ban on sterilisation procedures to prevent a 'diminishing Sinhala race' (Kodikara, 2014). At the same time, there are reports of women of Tamil ethnicity or Muslim faith being forced to use birth control with injectable contraceptives. Other reports have suggested that the continued military and police occupation of northern and eastern Tamil-populated states is fuelling a sex trafficking industry among the population of internally displaced returnees (most women) who traditionally relied on livelihoods from the land which is now military owned (ICAN, 2013). Young girls and women who are trafficked face being ostracised within their communities. It is suspected that many returning women are choosing not to report their experience of sexual violence to avoid stigma within their own community and to avoid risks of consequent sex trafficking, and that young girls are being forced to marry older men within their community (ICAN, 2013; Minority Rights Group International, 2013).

\section{The myth of the non-event}

Those perpetrating SGBV crimes during and after the Sri Lankan civil war have committed these crimes with anonymity and impunity by virtue of the gendered inequality and racism that the state permits and encourages (Kodikara, 2014; Sooka, 2014). In a United Nations Development Programme (UNDP)-commissioned report on Violence Against Women in the Asia Pacific, Sri Lanka had one of the highest rates (31 per cent) of male respondents reporting that they had committed non-intimate partner rape (Fulu et al., 2013, p. 41). $<$ xen $>^{12}</$ xen $>$ Across three provinces, including one Tamil-populated province in the north, Sri Lanka also had the highest percentage of men (95 per cent) who reported they had committed rape but were not punished for their act 
(Bangladesh and Indonesia were, respectively, second and third; Fulu et al., 2013, p. 45). The UNDP report reveals a pervasive impunity for egregious acts of gender violence: one-third of men self-report committing an act of non-intimate partner rape in a society where 95 per cent of men who admit to rape are not punished (Fulu et al., 2013; ICAN, 2013, p. 3). A recent World Bank study on violence against women in South Asia noted that Sri Lanka had 'one of the highest prevalence rates of violence against women' (Solotaroff \& Pande, 2014, p. 57).

A gendered analysis of sexism and racism in Sri Lanka demands that we scrutinise the accepted logic that LTTE soldiers did not engage in rape because there was a moral code against it to maintain group cohesion, and scrutinise allegations that the Sri Lankan military and police did so (only) because of a permissive environment of impunity. In fact, because of the permissive environment of impunity, the minority status of Tamil women and men, and the pervasive gender inequality across Sri Lankan society, we need to interrogate the silence around who did and did not commit SGBV crimes in Sri Lanka.

Local and international supporters of LTTE have as much of a vested interest in maintaining silence as the Sri Lankan government given that both face allegations of war crimes and systematic violations of human rights. Both sides have equally engaged in a war of propaganda during the decades-long civil war (Gupta, 2014). However, as the International Crisis Group reported (2007, p. 31), 'the government's human rights abuses have tended to take some attention away from LTTE violations. The lack of media access to LTTE areas also plays a part'. As noted in the UN Secretary-General Internal Review Panel report on Sri Lanka (2012) and the Human Rights Council (2014), both sides have committed human rights abuses. Specifically, the LTTE has reportedly committed 'political killings and refused to allow any pluralism or freedom of expression in areas' under their control (International Crisis Group, 2007, p. 1). The LTTE has been accused of forced abductions of children to secure village support, and the torture as well as murder of political opponents (Farr, 2009, p. 21; UN Secretary-General Internal Review Panel, 2012). Given the pervasive culture of impunity for sexual violence at the national level, it is hardly surprising that few Tamil individuals would be willing to come forward 
with sexual violence allegations against the LTTE. This is particularly so in an environment where the LTTE carries out extrajudicial killings against political opponents and the Sri Lankan security forces have acted in a climate of impunity and lawlessness.

The Report of the UN Secretary-General's Panel of Experts on Accountability in Sri Lanka determined that both sides had committed grave acts of sexual violence. It noted that both the Human Rights Watch and UN Special Representative for Children in Armed Conflict had concerns about the gendered forms of violence the LTTE were committing to increase conscript numbers and coerce civilian support (UN SecretaryGeneral Internal Review Panel, 2012, para. 151). Farr (2009, p. 21) argues that given the LTTE were engaging in other violations including forced abduction of children and the torture and extrajudicial killing of political opponents, it seems unlikely that they were not also engaging in acts of SGBV against these groups. Given the state of lawlessness and discrimination within Sri Lanka, it is surprising the degree to which scholars have interpreted the absence of allegations of SGBV against non-state armed groups as an absence of crimes. Even if there exist rebel groups and militaries that prohibit sexual violence, to suggest that the absence of reports indicates the absence of crime is misleading, especially given that the purpose of gender-based crimes is typically to secure silence and submission. In situations where sexual violence is 'opportunistic', military training and socialisation may be effective. However, in situations like postconflict Sri Lanka where SGBV is a gendered form of violent persecution delivered to achieve maximum political ends, socialisation techniques and legal prosecution regimes must work to overcome the gender norms that have permitted long-standing political and social impunity for these crimes.

\section{Implications for justice}

Current understandings of SGBV as a strategic 'weapon of war' or an opportunistic act in a permissible 'rape culture' fail to see the ways in which sexual violence may be a 'political' act. This is because they do not examine the gendered structural inequalities that make these acts thinkable and plausible before and during conflict. They do not see gender inequality as an inherently political phenomenon that determines the distribution 
of power and resources, and thus, which groups are subject to these SGBV crimes. We need to significantly improve our knowledge of when sexual violence is deployed as political violence, against whom, and why. Our analysis of the Sri Lanka conflict, particularly during the 2009-2014 post-conflict period, reveals a pattern of SGBV used to intimidate and silence political opposition. However, we can only understand the effectiveness of this violence if we understand the unequal gendered conditions in which sexualised violence takes place. SGBV is most effective in societies not merely because there is a culture of impunity for sexual and gender-based crimes but because political, economic and social structures create pervasive gender inequality. This environment of gendered inequality allows SGBV to be a widespread and systematic act deployed to further erode survivors' claims to retribution and restoration of their civil and political rights.

In the case of Sri Lanka, we know from their claims to asylum that both male and female human rights defenders and Tamil survivors of the 2009 war have experienced persistent harassment, sexual torture under arrest in their homes and continued sexual intimidation and harassment after release, as well as during the war itself (Sooka, 2014). Those who remain within Sri Lanka appear unable to report their experiences due to both the political danger and the social stigma within their family and their community.

In Sri Lanka, the use of SGBV to silence activists and the political opposition corresponds to a broader pattern of the denial of justice to those who have experienced physical and sexual violations. In a UNDP-commissioned report, Violence Against Women in the Asia Pacific, the survey (located across three provinces, including one Tamil-populated province) found that Sri Lanka had the third highest rate of male respondents reporting that they had committed non-intimate partner rape (31 per cent) (Papua New Guinea [44 per cent] and Indonesia [33 per cent]; Fulu et al., 2013, p. 41). However, Sri Lanka had the highest percentage of men who reported they had committed rape but were not punished for their act (95 per cent) (Fulu et al., 2013, p. 45). The UNDP report reveals that Sri Lanka has high levels of acceptance, amongst men and women, of families using violence to control female members (Fulu et al., 2013). Because these crimes are not considered to be crimes that should be recorded and 
investigated by the police, official figures on SGBV in Sri Lanka may be indicative of a silent epidemic (ICAN, 2013, p. 3).

In this broader context in Sri Lanka, SGBV becomes an effective, even legitimate form of political violence to (re-)establish gender order and ethnic dominance. It is facilitated by the fact that that there are few opportunities to receive reports on the extent to which this violence may be widespread and systematic among non-state armed groups versus state armed groups. Justice in this environment may be continually denied to survivors, who are expected to remain silent to preserve their status and/or safety. The adoption of the Human Rights Council Resolution in early 2014 led to the creation of a Commission of Inquiry to address the lack of evidence concerning war crimes and crimes against humanity committed by all parties near the end of the civil war, and in the years following (UN Human Rights Council, 2014). The outcome of this commission is currently unknown with change of government in Sri Lanka in late 2014 leading to a delay in the release of the commission's report (originally scheduled for March 2015).

Until the Sri Lankan government conducts its own enquiry into the actions of all parties during the civil war (and afterwards), there will be few opportunities within the country to investigate and uncover the true of extent of SGBV crimes. State-level recognition of the extent of these crimes begins to restore the criminal and legal redress for these crimes, and it will help to achieve international recognition of the need for collective reparations to be targeted at survivors of SGBV and to address the economic, social and political disempowerment that has been produced from such violence. In recognising that this violence has taken place, there is an opportunity not only to identify the perpetrators, but to identify the pattern of systematic and widespread targeting that occurred. With this understanding, Sri Lanka can then begin addressing the politics of exclusion and institutional shortcomings that led to these populations being attacked in the first place.

In a country such as Sri Lanka, with entrenched patriarchy across its social, political and economic institutions, combined with the extreme vulnerability of ethnic, religious or political minorities, the non-reporting of SGBV cannot constitute good 
evidence that sexual violence has not been systematically employed. We contend that the failure to predict the sexual violence that occurred in Sri Lanka and to explain the continued prevalence of SGBV since 2009 is due to a general failure of political science scholarship. In particular, scholarship on the causes of sexual violence in conflict has failed to appreciate how the scale of gendered inequality in the Sri Lankan community, taken together with the political oppression of those critical of the Sri Lankan government, constrains reporting of any SGBV violence.

\section{Conclusion}

Current research on mass sexual violence tends to view it as a by-product of armed conflict, either as opportunistic acts that occur in the theatre of war (Cohen, 2013; Wood, 2006) or as instrumental acts of war used to achieve other tangential aims, such as displacement, seizure of land and political repression (Farr, 2009). These studies conceive gendered structural conditions within a society as pervasive across all conflicts, and as part of the normal(ised) background to conflict. However, they do not conceptualise SGBV specifically as an act of political violence. We contend that this research fails to attend to the powerful effects their knowledge claims have in international politics, in this case silencing and reinforcing gendered discrimination and the culture of impunity for SGBV (Ackerly \& True, 2008; Kirby, 2012). The risk of such studies is a failure to consider the relationship between gender inequality and genderbased crimes, potentially compounding the likelihood that victims, especially women and girls, will be denied access to justice. As Daly (this volume) describes, the 'dark figure' of non-reported, non-adjudicated and non-convicted cases of sexual violence risks amplification when the political violence of SGBV is underplayed or ignored.

At present, causal research on SGBV has not adequately appreciated the politicised context of sexual violence reporting and data collection on the ground. Very real challenges with sexual violence data collection, including gaining access to SGBV reports, has led researchers to analyse the causes of sexual violence globally with incomplete data, despite the potential biases and selectivity of this approach. For instance, scholars have narrowed their focus to a particular type of armed conflict, 
perpetrator or form of sexual violence where the data exist but not necessarily where the problem lies (The Lancet, 2014). Most studies relying on quantitative analysis of existing data sets or on secondary qualitative data do little to contextualise the serious limitations of the data. Equally problematic is that much of this research has assumed that because gender inequality is everywhere it cannot logically explain SGBV anywhere. From a feminist methodological perspective, such a conclusion is not justified objectively by the research question. The multifaceted concept of gendered inequality is poorly operationalised in the majority of causal studies, and thus structural gender discrimination cannot be ruled out as an explanation for widespread and systematic sexual violence. At the very least, to allow us to assess their knowledge claims, scholars should highlight the limitations of their research designs on sexual violence in conflict. Even if a crucial cause of sexual violence is a social environment that enables perpetrators, it is not the sole cause and the gendered social construction and legitimation of perpetrators' attitudes, values, beliefs and interests must also be explained. The latter are intimately related to the 'value' of women and men and their political, economic and social relationships in a given society.

A gendered perspective on mass SGBV is crucial for the prevention of conflict. Current policy recommendations on conflict-related sexual violence focus on ending impunity for individual (male) perpetrators and addressing the lack of hierarchy and rape prohibition norms within armed groups. Such recommendations neglect to examine the significance of gendered inequalities and discriminatory practices that make the use of sexualised violence extremely effective and especially harmful in destabilising communities, and likely to continue to be used while gendered inequalities and discrimination endure. Though in some cases armed groups consciously choose sexual violence, it is not so much the active intent that makes sexual violence in times of conflict a concern, but how in their aggregation these activities serve to reinforce the material relations of inequality between men and women during and after conflict and the culture of impunity. Without the tools of gender analysis we cannot understand the material structures and cultural orders of perpetrators and the victim-survivors of conflict-related SGBV. This lack of knowledge undermines our effort to end this violence. In particular, the prevention of future SGBV violence must direct attention to the survivors of past 
SGBV crimes by creating political spaces for their representation in post-conflict institutions. It must also provide opportunities for the redistribution of material resources to eliminate structural gender inequalities. The focus on prevention, moreover, demands that we rethink the retribution focus on perpetrators and resist efforts to restore the preconflict gender order.

\section{Notes}

$<$ en-group type $=$ endnotes $>$

$<$ en $><$ label $>1</$ label $>$ See United Nations Security Council [UNSC], S/Res/1820 (19 June 2008); S/Res/1888 (30 September 2009); S/Res/1889 (5 October 2009); S/Res/1960 (16 December 2010); S/Res/2106 (24 June 2013); S/Res/2122 (18 October 2013). </en> $<$ en $><$ label $>2</$ label $>$ UN Security Council Resolution S/Res/2106 (June 2013). $<$ en $>$ $<$ en $><$ label $>3<$ label $>$ See Bastick et al. (2007); Butler et al. (2007); Cohen (2013); Cohen and Nordas (2014); Farr (2009); Green (2006); Mroz (2011); Nordas and Cohen (2012); Wood $(2006,2009) .</$ en $>$ $<$ en $><$ label $>4</$ label $>$ Examples of a critical feminist analysis of the root causes of sexual violence in conflict include Baaz and Stern (2013); Cockburn (2010); D’Costa (2011); Enloe (2000); Henry and Kirby (2012); Mackenzie (2012).</en> $<$ en $><$ label $>5</$ label $>$ Wood (2006, pp. 325-326) also questions the relationship between gender and sexual violence in conflict by asking why gender inequality produces sexual violence in one setting, but in another leads to the participation of women in rebel militias. $</$ en $>$ 
$<$ en $><$ label $>6</$ label $>$ Similarly, Green (2006) finds that the presence of ethnic cleavages was most likely informed by the presence of conflict, and as such, was not strongly correlated with the presence of SGBV. These findings are corroborated by Cohen (2013); Nordas and Cohen (2012); and Wood (2006, 2009).</en>

$<$ en $><$ label $>7</$ label $>$ The relationship between gender equality and fertility rates is a Jshaped curve; that is, after initially declining with greater gender equality, fertility increases, as observed in countries which come closest to gender parity in education and economic and political participation, such as Sweden and New Zealand (Myrskyla et al., 2009). $</$ en $>$

$<$ en $><$ label $>8</$ label $>$ Quijano and Kelly (2012, p. 489, n. 154) note in a personal communication with Cohen: 'scholars who study wartime killing are rarely asked to calculate rates of pre-war murder to determine if the culture was especially murderous before the outbreak of conflict'. $</$ en $>$

$<$ en $><$ label $>9</$ label $>$ SGBV studies that examine direct deaths due to armed conflict do not include indirect deaths in their analysis (Farr, 2009; Mroz, 2011).</en> $<$ en $><$ label $>10</$ label $>$ Sri Lanka has the lowest representation of women in parliament in South Asia, at 5.8 per cent (Solotaroff \& Pande, 2014, p. 77). $</$ en $>$ $<$ en $><$ label $>11</$ label $>$ The government provides rupee cash benefits to military and police personnel (overwhelmingly Sinhalese) who have a third child (Kodikara, 2014). $</$ en $>$ $<$ en $><$ label $>12</$ label $>$ Only Papua New Guinea (44 per cent) and Indonesia (33 per cent) reported higher rates of non-intimate partner rape than Sri Lanka. $</$ en $>$ 
$<$ en-group $>$

\section{References}

Ackerly, B. and True, J. (2008) 'Reflexivity in Practice: Power and Ethics in Feminist Research on International Relations', International Studies Review, 10(4), 693-707.

Baaz, M. E. and Stern, M. (2013) Sexual Violence as a Weapon on War? (London: Zed Books).

Bastick, M., Grimm, K. and Kunz, R. (2007) Sexual Violence in Armed Conflict: Global Overview and Implications for Security Sector (Geneva: Geneva Centre for the Democratic Control of Armed Forces).

Butler, C. K., Gluch, T. and Mitchell, N. J. (2007) 'Security Forces and Sexual Violence: A Cross-National Analysis of a Principal Agent Argument', Journal of Peace Research, 4, 669-687.

Buvinic, M., Das Gupta, M., Casabonne, U. and Verwimp, P. (2013) 'Violent Conflict and Gender Inequality: An Overview', World Bank Research Observatory, 28(1), 110138.

Cockburn, C. (2010) 'Gender Relations as Causal in Militarization and War: A Feminist Standpoint', International Feminist Journal of Politics, 12(2), 139-157.

Cohen, D. K. (2013) 'Explaining Rape during Civil War: Cross-National Evidence (1980-2009)', American Political Science Review, 107(3), 461-477.

Cohen, D. K. and Nordas, R. (2014) 'Sexual Violence in Armed Conflict: Introducing the SVAC Dataset, 1989-2009', Journal of Peace Research 51, 418-428. 
Connell, R. W. (1990) 'The State, Gender and Sexual Politics: Theory and Appraisal', Theory and Society, 19(5), 507-544.

D'Costa, B. (2011) Nationbuilding, Gender and War crimes in South Asia (London; New York: Routledge).

Enloe, C. (2000) Manoeuvres: The International Politics of Militarizing Women's Lives (Berkeley, CA: University of California Press).

Farr, K. (2009) ‘Extreme War Rape in Today’s Civil-War-Torn States: A Contextual and Comparative Analysis', Gender Issues, 26(1), 1-41.

Fearon, J. D. and Laitin, D. D. (2003) 'Ethnicity, Insurgency, and Civil War', American Political Science Review, 97(1) 75-90.

Fulu, E., Warner, X., Miedema, S., Jewkes, R., Roselli, T. and Lang, J. (2013) Why Do Some Men Use Violence Against Women and How Can We Prevent It? Quantitative Findings from the United Nations Multi-country Study on Men and Violence in Asia and the Pacific (Bangkok: UNDP, UNFPA, UN Women and UNV); retrieved from http://www.partners4prevention.org/node/515

Ghobarah, H. A., Huth, P. and Russett, B. (2004) 'Comparative Public Health: The Political Economy of Human Misery and Well-Being', International Studies Quarterly, 48(1), 73-94.

Goetz, A. (2008) 'Women Targeted Or Affected By Armed Conflict: What Role For Military Peacekeepers?' Conference Summary Report, 27-29 May 2008, Wilton Park, Sussex, UNIFEM, June; retrieved from 
http://www.securitycouncilreport.org/atf/cf/\%7B65BFCF9B-6D27-4E9C-8CD3-

CF6E4FF96FF9\%7D/WPS\%20SUMMARY\%20REPORT\%20WP.doc

Goldstein, J. (2001) War and Gender: How Gender Shapes the War System and Vice Versa (New York: Cambridge University Press).

Green, J. L. (2006) 'Collective Rape: A Cross-National Study of the Incidence and Perpetrators of Mass Political Sexual Violence, 1980-2003', submitted PhD thesis, Ohio University.

Gupta, R. (2014) 'Sri Lanka Women in Conflict', Open Democracy 50.50, 7 March 2014; retrieved from https://www.opendemocracy.net/5050/rahila-gupta/sri-lanka-women-inconflict

Henry, M. and Kirby, P. (2012) 'Rethinking Masculinity and Practices of Violence in Conflict Settings', International Feminist Journal of Politics, 14(4), 445-449.

Human Security Report Project (2012) Human Security Report 2012: Sexual Violence, Education, and War: Beyond the Mainstream Narrative (Vancouver: Human Security Press).

ICAN (International Civil Society Action Network) (2013) 'Elusive Peace, Pervasive Violence: Sri Lankan Women's Struggle for Security and Justice', What the Women Say, Report Brief No. 8, Spring; retrieved from http://www.icanpeacework.org/wpcontent/uploads/2013/06/Slanka-final.pdf

International Crisis Group (2007) 'Sri Lanka’s Human Rights Crisis', Asia Report, No. 135, 14 June; retrieved from http://www.crisisgroup.org/ /media/Files/asia/south-asia/srilanka/135_sri_lanka_s_human_rights_crisis.pdf 
Kirby, P. (2012) 'How is Rape a Weapon of War?: Feminist International Relations, Modes of Critical Explanation and the Study of Wartime Sexual Violence', European Journal of International Relations, 19(4), 797-821.

Kodikara, C. (2014) 'State Racism and Sexism in Post-war Sri Lanka', Open Democracy, 10 November; retrieved from https://www.opendemocracy.net/5050/chulanikodikara/state-racism-and-sexism-in-postwar-sri-lanka Mackenzie, M. (2012) Female Soldiers in Sierra Leone: Sex, Security and Post-Conflict Development (New York: New York University Press).

Minority Rights Group International (2013) 'Living with Insecurity: Marginalization and Sexual Violence Against Women in North and East Sri Lanka', Minority Rights Group International Report; retrieved from http://www.minorityrights.org/download.php@id=1297

Mroz, M. (2011) Wartime Sexual Violence: The New Kalashnikov? A Test of Three Hypotheses on the Use of Sexual Violence as a Weapon of War (Saarbrucken: Verlag). Myrskyla, M., Kohler, H-P. and Billari, F. (2009) ‘Advances in Development Reverse Fertility Declines', Nature, 460, 741-743.

Nordas, R. and Cohen, D. K. (2012) Sexual Violence by Militias in African Conflicts: Not a Question of ‘Delegation' by States, CSCW Policy Brief 1; retrieved from http://file.prio.no/publication_files/cscw/Nordas-Cohen-Sexual-Violence-MilitiasAfrican-Conflicts-CSCW-Policy-Brief-01-2012.pdf 
Office of the ICC Prosecutor (2014) Policy Paper on Sexual and Gender-Based Crimes, June; retrieved from http://www.icc-cpi.int/iccdocs/otp/OTP-Policy-Paper-on-Sexualand-Gender-Based-Crimes--June-2014.pdf

Quijano, A. A. and Kelly, J. (2012) 'A Tale of Two Conflicts - an Unexpected Reading of Sexual Violence in Conflict through the Cases of Colombia and Democratic Republic of Congo', in Morten Bergsmo, Alf B. Skre and Elisabeth Jean Wood (eds.) Understanding and Proving International Sex Crimes (Oslo: Torkel Opsahl Academic Epublisher), 437-494.

Security Council Report (2014) Cross-Cutting Report on Women Peace and Security: Sexual Violence in Conflict and Sanctions; retrieved from http://www.securitycouncilreport.org/women-peace-and-security/ Solotaroff, J. L. and Pande, R. P. (2014) Violence against Women and Girls: Lessons from South Asia, World Bank Group; retrieved from https://openknowledge.worldbank.org/handle/10986/20153

Sooka, Y. (2014) An Unfinished War: Torture and Sexual Violence in Sri Lanka, 20092014, Bar Human Rights Committee; retrieved from https://barhumanrights.org.uk/sites/default/files/documents/news/an_unfinihsed_war._tor ture_and_sexual_violence_in_sri_lanka_2009-2014_0.pdf

The Lancet (2014) 'Ending Sexual Violence in Conflict and beyond', The Lancet, 383 (9934), 2019.

True, J. (2012). The Political Economy of Violence against Women (New York: Oxford University Press). 
UN General Assembly (1998) Rome Statute of the International Criminal Court, 17 July 1998; retrieved from http://www.unhcr.org/refworld/docid/3ae6b3a84.html

UN Human Rights Council (2014) Promoting Reconciliation and Accountability in Sri Lanka, 26 March 2014, A/HRC/25/L.1/Rev.1 2014.

UN Secretary-General (2012) Conflict Related Sexual Violence, Report of the SecretaryGeneral Prevention of Sexual Violence in Armed Conflict, S/2012/33.

UN Secretary-General (2013) Conflict Related Sexual Violence, Report of the SecretaryGeneral, Prevention of Sexual Violence in Armed Conflict, S/2013/149.

UN Secretary-General (2014) Conflict Related Sexual Violence, Report of the SecretaryGeneral, Prevention of Sexual Violence in Armed Conflict, S/2014/181.

UN Secretary-General Internal Review Panel (2012) Report of the Secretary-General's Internal Review Panel on United Nations Action in Sri Lanka, November; retrieved from http://www.un.org/News/dh/infocus/Sri_Lanka/The_Internal_Review_Panel_report_on_ Sri_Lanka.pdf

United Kingdom (UK) Foreign Commonwealth Office (FCO) (2014) Summit Report: Global Summit to End Sexual Violence in Conflict. 10 December; retrieved from https://www.gov.uk/government/publications/summit-report-the-global-summit-to-endsexual-violence-in-conflict-june-2014

UNSC [United Nations Security Council](2000) Resolution 1325, S/RES/1325.

UNSC [United Nations Security Council] (2008) Resolution 1820, S/RES/1820.

UNSC [United Nations Security Council] (2009a) Resolution 1888, S/RES/1888. 
UNSC [United Nations Security Council] (2009b) Resolution 1889, S/RES/1889.

UNSC [United Nations Security Council] (2010) Resolution 1960, S/RES/1960.

UNSC [United Nations Security Council] (2013a) Resolution 2106, S/RES/2106.

UNSC [United Nations Security Council] (2013b) Resolution 2122, S/RES/2122.

Wood, E. J. (2006) 'Variation in Sexual Violence During War', Politics and Society, 34(3), 307-342.

Wood, E. J. (2009) 'Armed Groups and Sexual Violence: When is Wartime Rape Rare?', Politics and Society, 37(1), 131-162.

Wood, E. J. (2012) 'Rape during War is Not Inevitable: Variation in Wartime Sexual Violence', in M. Bergsmo, A. B. Skre and E. J. Wood (eds.) Understanding and Proving International Sex Crimes (Oslo: Torkel Opsahl Academic Epublisher), 389-419. 